\title{
Ensino de inglês no PROFICI e no NucLi UFBA (Programa Idiomas sem Fronteiras) em tempos de pós-método e internacionalização: convergências e especificidades
}

Fernanda Pereira ${ }^{1}$

\begin{abstract}
Resumo
\end{abstract}
Sob uma perspectiva teórico-explanatória, este artigo aborda o ensino de língua inglesa em tempos de pósmétodo e de ampliação de ações voltadas ao processo de internacionalização das universidades, tendo como objeto de análise estratégias usadas em salas de aula dos cursos oferecidos por um programa institucional de ensino de idiomas da Universidade Federal da Babia (PROFICI) e o Núcleo de Linguas desta universidade, no âmbito do Programa Idiomas sem Fronteiras. Em seu escopo, são discutidas convergências e especificidades desses dois contextos, mostrando a profícua articulação de suas ações, que expressam o protagonismo da área de Letras através do ensino de línguas estrangeiras como alicerce para o processo de internacionalização.

Palavras-chave: NucLi. PROFICI. Ensino. PósMétodo. Internacionalizạ̧ão

\footnotetext{
${ }^{1}$ Universidade Federal da Bahia.
} 


\section{Ponto de partida}

O fenômeno da internacionalização das universidades não é recente, mas foi ampliado a partir de 2011 com a implementação do programa de mobilidade estudantil Ciência sem Fronteiras (CsF) (BRASIL, 2015; MANÇOS e COELHO, 2017). Embora seja visto por alguns estudantes e professores da área de Letras sob a sombra do ressentimento por não ter contemplado em seus editais esse campo de saber, o programa redimensionou, indiretamente, a importância de professores de línguas estrangeiras para o processo de internacionalização das universidades, devido ao seu papel fundamental na preparação linguística dos candidatos ao programa com consequentes reverberações para o desenvolvimento da área de ensino e aprendizagem de línguas estrangeiras.

O papel fundamental de professores de línguas estrangeiras despontou desde o início do CsF mediante o levantamento de dados iniciais sobre o destino escolhido pelos candidatos, que revelou uma escolha controversa em relação a um dos objetivos do programa: o aprimoramento linguístico. Muitos estudantes escolheram Portugal como destino (PAIVA, 2014) por ser um país onde, assim como no Brasil, se fala português, o que denunciou uma lacuna referente a um fator imprescindível para a materialização dos propósitos de intercâmbio: a proficiência em língua estrangeira.

Nesse contexto, em 2012, emergiu o Programa Inglês sem Fronteiras (ABREU-ELIMA et al., 2016) - que se tornou Idiomas sem Fronteiras em 2014 - trazendo a oportunidade para estudantes da área de Letras atuarem em cursos oferecidos em universidades federais pelos Núcleos de Língua (NucLis) regidos por esse programa. Os professores que atuam nos NucLis recebem uma bolsa concedida pela Coordenação de Aperfeiçoamento de Pessoal de Nível Superior (CAPES) e um investimento consistente em formação em uma vertente pouco explorada no campo de ensino de línguas estrangeiras no Brasil, qual seja: o ensino de língua estrangeira para fins específicos (ELFE). Tais fins estão atrelados ao projeto de internacionalização das universidades e, portanto, têm em horizonte o contexto acadêmico. Desse modo, nas aulas do NucLi, as situações de uso da língua estrangeira são dimensionadas conforme interações que ocorrem na universidade, preparação para palestras e aulas, produção e leitura de artigos científicos e outros gêneros textuais análogos, para citar alguns exemplos.

Os fins específicos que qualificam o tipo de ensino implementado no Programa Inglês sem Fronteiras figuram não apenas como fins, mas, também, como meios. Mediante 
essa modalidade de aula, os aprendizes estudam língua estrangeira enquanto também têm lições sobre um propósito palpável para aprendê-la, ou seja, desenvolver competências e habilidades necessárias para comunicação em contexto acadêmico internacional no bojo de um objetivo que transcende o plano individual e local, resvalando para um projeto nacional de abertura de fronteiras entre saberes produzidos em universidades no Brasil e no exterior. Nesse sentido, nas aulas, os aprendizes também são sensibilizados a vislumbrar esse tipo de universidade que se expande para o intercâmbio de conhecimentos em nível global.

É importante mencionar que as aulas ministradas nos NucLis não se limitam ao ensino de língua estrangeira para fins específicos. No que se refere ao NucLi UFBA, nele são colocadas em prática variadas estratégias oriundas de diversos métodos, em alinhamento com a noção de pós-método (KUMARAVADIVELU, 2003), cujos pressupostos serão abordados neste artigo.

Para alcançar objetivos de capacitação da comunidade universitária para a finalidade da internacionalização, a formação de professores de língua estrangeira passou a ser uma meta. Tendo essa demanda em horizonte, reflexões e experiências sobre o processo de formação de professores do NucLi UFBA e do PROFICI protagonizarão as discussões empreendidas neste artigo com o intuito de compartilhar e ressignificar estratégias de ensino de língua estrangeira e o papel de professores da área de Letras na construção de uma comunidade de saberes internacionais.

Os benefícios da sólida formação de estudantes em cursos de Letras para atuarem como professores não se limitam a esse campo do saber. Eles são extensivos a estudantes de outras áreas que não tiveram a chance de atravessar fronteiras nacionais, como os contemplados pelo CsF, mas que, através dos cursos oferecidos pelo NucLi e PROFICI, adquirem o passaporte principal necessário à travessia para saberes internacionais: a proficiência em língua estrangeira.

\section{Internacionalização, NucLi UFBA e PROFICI}

A relação entre o $\mathrm{CsF}$ e a internacionalização das universidades brasileiras é explicitada pelo decreto que instituiu o programa em 2011, em que se lê, entre os seus objetivos: "contribuir para o processo de internacionalização das instituições de ensino 
superior e dos centros de pesquisa brasileiros" (BRASIL, 2011). Antes desse programa, a mobilidade estudantil no Brasil contemplava a pós-graduação em nível de mestrado e doutorado bem como outros pesquisadores (IOSIF et al., 2016). Todavia, com a criação do CsF, a mobilidade envolveu, também, estudantes de graduação, representando uma inovação e uma grande oportunidade de expansão de redes internacionais de saberes e pesquisas também nesse estágio. Ademais, a variedade de países como opção de intercâmbio foi ampliada diante dos acordos firmados com mais de trinta países.

No cerne dos objetivos do CsF, leem-se propósitos expressos por palavras como "empreendedorismo", “competitividade”, “inovação" (BRASIL, 2011). Esses termos, aliados ao projeto de internacionalização, passaram por interpretações que os relacionaram a um propósito neoliberal de educação. Essa interpretação foi acentuada com a exclusão das áreas de Humanas e Letras (BORGES, 2015) e o uso de critérios como desempenho acadêmico na seleção dos bolsistas. Para Borges, "[a]o explicitar critérios de seleção para as bolsas do CsF com base no desempenho e potencial acadêmico (CAPES; CNPq, 2011, p. 11), inclusive maior fluência em língua estrangeira, desatrelados do princípio de equidade, o Programa beneficiou os já historicamente privilegiados” (BORGES, 2015, p. 171).

Críticas como as feitas por Borges atuaram na construção de uma imagem negativa do CsF que, em certos momentos, encobre a contribuição do programa para a inserção do país na comunidade acadêmica internacional. Tais críticas também desconsideram uma das atribuições do Ministério da Educação, trazida no decreto que instituiu o CsF, qual seja: "III - promover o ensino e a aprendizagem de idiomas estrangeiros" (BRASIL, 2011). Essa atribuição, que parecia ser apenas mais uma diante de todas as elencadas no referido documento, tomou uma proporção metonímica, passando a ser a parte - ensino de língua estrangeira - sem a qual o todo não atingiria uma efetividade. Através dessa metonímia, a comunidade também redimensionou o papel das línguas estrangeiras, acentuando a sua importância para o desenvolvimento científico e priorizando-as como um passaporte fundamental para comunidades científicas internacionais. Esse fato tem caráter inegavelmente significativo em um país de ampla resistência à quebra do monolinguismo.

As experiências com o CsF demonstraram que a teia complexa e dinâmica de suas articulações dependia de um ponto fulcral: a proficiência em língua estrangeira. Esse aspecto fundamental promoveu as bases para a criação do Programa Inglês sem Fronteiras e colocou em evidência as lacunas na educação básica. De acordo com Borges (2015), 
Os cursos de imersão no exterior e a política de aperfeiçoamento da língua inglesa aos estudantes das universidades federais, apesar de amenizar as necessidades imediatas do intercâmbio, em sua primeira etapa, não chegam às raízes do problema, fincadas, em geral, no ensino inadequado e ineficiente das escolas de educação básica (BORGES, 2015, p. 172-173).

Como pontos de crítica ao CsF, a autora sublinha, ainda, a sua ineficácia em contribuir com a educação básica e a penalização de estudantes com baixa fluência ou nenhum conhecimento da língua estrangeira, imprimindo uma política de exclusão, que contradiz o elevado número de bolsas destinado pelo programa. No âmbito dessa contradição, Borges desconsidera, contudo, o fato de que muitos estudantes com baixa ou nenhuma fluência em língua estrangeira aceitaram o desafio de aprendê-la no exterior ou intensificaram seus estudos de língua estrangeira com o objetivo de participar do programa, sendo sensibilizados, talvez pela primeira vez, sobre a importância de aprender um idioma e escapar do monolinguismo.

As lentes de pesquisadores que se debruçam sobre um objeto ou um determinado fenômeno não são capazes de captar os mais variados matizes que compõem uma problemática. Nesse sentido, cada pesquisa é um recorte e cabe aos leitores e outros pesquisadores trazerem à tela matizes outros não contemplados na paisagem desenhada. A busca por outros matizes revela que, apesar da ausência de uma política estruturada em estágios para construção estratégica de acomodação do CsF, houve a configuração de uma série de ações pautadas nas necessidades da comunidade acadêmica em face ao CsF. Essas ações tiveram, como ponto de partida, estudos realizados por um Grupo de Trabalho composto por 20 especialistas de universidades federais da área de Letras e Ensino a Distância (ABREU-E-LIMA et al., 2016).

O resultado do referido grupo de trabalho apontou para a necessidade de aplicação de testes de proficiência pelas próprias universidades, como uma das ações para diagnosticar o grau de preparação dos estudantes para o programa e o aprendizado ou aprimoramento do conhecimento de língua estrangeira através de cursos a distância e presenciais (ABREU-E-LIMA et al., 2016). Esse grupo que pertenceu ao processo de construção do Programa Inglês sem Fronteiras passou por reconfigurações, mas a rede de especialistas voltados a pensar o ensino de línguas estrangeiras no país continua e tem se ampliado a cada ano. 
Em meio às necessidades apontadas pelo grupo de estudo preliminar supracitado, a proficiência linguística foi o principal fator e a evidência acerca das lacunas em termos de formação de falantes de línguas estrangeiras (ABREU-E-LIMA et al., 2016) deixou de ser assunto pautado em senso comum para se tornar o ponto principal de ação do Programa Inglês sem Fronteiras, criado pelo Decreto n ${ }^{\circ}$ 7642. O programa apresentou três propostas fundamentais de suporte para o CsF, a saber: oferta do exame de proficiência de língua inglesa TOEFL/ITP, que avalia as habilidades de compreensão oral e escrita e conhecimento de estruturas gramaticais, aplicado nas próprias universidades que se tornaram Centros Aplicadores desse exame; diagnóstico de proficiência também através desse exame; e oferta de cursos gratuitos na modalidade presencial através dos NucLis e à distância com o My English Online (MEO).

Ao refletir sobre o CsF e o Inglês sem Fronteiras, opera-se uma inversão imaginária na relação entre eles e, assim, acredita-se que o $\mathrm{CsF}$ teve um início, com propósitos mais efetivos, após a criação do Programa Inglês sem Fronteiras. Apenas após a implementação deste, foi possível assegurar o pré-requisito mínimo para participação dos estudantes no CsF, não só pela ampla oferta do exame de proficiência TOEFL/ITP, mas, sobretudo, pela oferta do MEO e de cursos presenciais nos NucLis, que deram um suporte fundamental aos estudantes e até mesmo auxiliaram a propagar o CsF e outros programas de mobilidade. Desse modo, é possível afirmar que o Programa Inglês sem Fronteiras não só ensinou inglês como também atuou no aprendizado sobre a importância da mobilidade e da internacionalização ao encurtar a distância entre a comunidade acadêmica e esses objetivos, por trazer esses temas como conteúdos de suas aulas.

Diante do protagonismo das línguas estrangeiras no $\mathrm{CsF}$ e no processo de internacionalização, as bolsas não concedidas para graduandos e pós-graduandos de Letras para participação em intercâmbios pelo $\mathrm{CsF}$ foram destinadas a estudantes dessa área para ensinar línguas estrangeiras. E, mesmo com a extinção do CsF, o Programa Idiomas sem Fronteiras (IsF) continua e teve suas ações redesenhadas para atender não somente $\mathrm{o}$ ensino superior, mas, também, a educação básica. Essa ampliação é estabelecida pela Portaria Normativa n ${ }^{\circ} 30 / 2016$, segundo a qual:

Art. $1^{\circ}$. Fica instituído o Programa Idiomas sem Fronteiras - IsF, com a finalidade de propiciar a formação inicial e continuada e a capacitação em idiomas de estudantes, professores e corpo técnico-administrativo das Instituições de Educação Superior - IES Públicas e Privadas e da Rede Federal de Educação Profissional, Científica e Tecnológica - RFEPCT, 
de professores de idiomas da rede pública de Educação Básica, bem como a formação e a capacitação de estrangeiros em língua portuguesa, contribuindo para o desenvolvimento de uma política linguística para o país (BRASIL, 2016).

A relevância do IsF transcendeu as fronteiras dos seus propósitos iniciais e se amalgamou a um projeto maior que convergiu no objetivo de democratizar o acesso às línguas estrangeiras com ações extensivas à educação básica. Os agentes desse processo Núcleo Gestor, coordenadores e professores que ministram as aulas - são profissionais da área de Letras, e, em especial, licenciatura. Assim, com o IsF, nota-se que as ações em torno da internacionalização promoveram as bases para a criação de uma gama de objetivos nacionais alinhados por esse programa sem fronteiras.

Em âmbito local, também houve reverberações do CsF e da meta de internacionalização em relação à aprendizagem de línguas estrangeiras, resultando na iniciativa da Universidade Federal da Bahia de instituir um programa de Proficiência para Estudantes e Servidores da universidade (PROFICI) inteiramente gratuito em 2012. O objetivo geral do programa é capacitar a comunidade acadêmica para a internacionalização da universidade, tendo como um ponto de ação o aprendizado de idiomas como suporte basilar para o processo de internacionalização.

Com a oferta de 5 idiomas, o PROFICI contemplou, já em sua primeira edição, 1.866 estudantes e servidores. De 2012 a 2017, 20.907 matrículas foram realizadas e 198 estudantes de graduação e pós-graduação já atuaram como monitores, como são chamados os estudantes de graduação ou pós-graduação que ministram as aulas. Em 2014, mais um idioma foi acrescentado ao elenco de cursos do programa: português como língua estrangeira.

Os objetivos do PROFICI estão alinhados desde o início do programa ao propósito da internacionalização. Todavia, com a implementação do Núcleo de Línguas, no âmbito do IsF na UFBA em 2015, e com a aplicação de estratégias guiadas pelos princípios do Ensino de Inglês para Fins Específicos, a relação entre ensino de línguas e internacionalização se tornou mais evidente e veemente.

Há convergências e diferenças entre o PROFICI e o NucLi que merecem ser mencionadas para esclarecer e deslocar possíveis hipóteses de sobreposição. Elas serão abordadas no tocante às estratégias usadas em ambos os espaços de ensino de língua estrangeira. É válido assinalar que as reflexões enfocam a língua inglesa. 


\section{Ensino de inglês no PROFICI e no NucLi UFBA em tempos de pós-método e internacionalização: convergências e especificidades}

A história do ensino de língua estrangeira é marcada pela ascensão e declínio de variados métodos (BROWN, 2007). A forma sequenciada com que esses métodos são apresentados em livros de metodologia denota a tentativa de criação de um novo método para suprir lacunas ou mesmo reverter os princípios que regiam o anterior. Essa premissa pode ser ilustrada pela transição do Método de Tradução e Gramática para o Método Audiolingual e deste para o Community Language Learning, por exemplo. Após várias transições, o Método Comunicativo surgiu como um divisor de águas e como aquele que promoveria, de forma supostamente "completa", um aprendizado efetivo da língua estrangeira - premissa que se mostrou amplamente refutável.

O Método Comunicativo tem como algumas de suas características o uso de linguagem autêntica e o ensino através de functions, que, de acordo com Brown (2007), se referem a atos realizáveis através do uso da língua, como pedir, perguntar, aceitar, entre outros. Esses dois elementos são concebidos como fatores que tornam o processo de ensino de língua estrangeira mais próximo do mundo empírico mediante a contextualização dos conteúdos aprendidos com cenas que são simuladas como "reais".

Todavia, há ressalvas em relação ao suposto caráter "real" das atividades desenvolvidas em sala de aula. No tocante a tal caráter, atrelado à noção de autenticidade e de functions, Kumaravadivelu (2006) apresenta argumentos que o problematizam no Método Comunicativo. De acordo com esse autor, as situações comunicativas criadas em sala de aula nem sempre espelham interações genuínas, existentes no mundo fora da sala de aula, por serem essas inesperadas e espontâneas e, portanto, fora de uma previsibilidade que marca as situações didáticas. Além disso, observações feitas por autores como Nunan (KUMARAVADIVELU, 2006) mostraram o predomínio da forma ao invés de functions em aulas examinadas por ele. Tais observações denotam que nem sempre os objetivos delineados por um método, em um estilo top-down, convergem com a realidade do contexto em que ele é usado.

Ao lado dessas questões, é pertinente compartilhar uma situação comum no ensino de língua inglesa, marcada pela intrigante circunstância de o aprendiz ter uma aula sobre uma determinada function, como se despedir, por exemplo, e, ao término dela, usar essa function em língua materna, despedindo-se do professor em português. Casos como esse 
demonstram que a transposição entre o que se aprende em sala de aula e as interações sociais nem sempre é evidente para os aprendizes.

A problematização de aspectos do Método Comunicativo permite pensar, na esteira de Kumaravadivelu, que não há um método soberano, alinhado a qualquer contexto e capaz de atender, de forma ampla, às necessidades dos aprendizes. Essa constatação pavimentou o caminho para a Condição do Pós-método, que, ao invés de consistir em um "método alternativo" (KUMARAVADIVELU, 2003, p. 33, tradução nossa), se refere à "busca por uma alternativa para o método" (KUMARAVADIVELU, 2003, p. 32, tradução nossa). A partir dessa condição, insurge a Pedagogia do Pós-Método.

É pertinente atentar para questões epistemológicas que antecedem a Pedagogia do Pós-Método e substanciam a ascensão e declínio dos métodos e a posterior suposta soberania do Método Comunicativo. A transição entre os diferentes métodos enuncia, como pressuposto implícito, a noção de que é possível encontrar um método capaz de promover a aprendizagem de forma efetiva e totalizante. Essa concepção conflui com uma visão epistemológica, predominante até a modernidade, mas ainda passível de ser vislumbrada, em que a "verdade" e a "totalidade" figuram como termos chave (HALL, 2003). Em contraste a esses termos, reflexões sobre pós-modernidade trouxeram à baila noções de descentramento, descontinuidade e fragmentação (HALL, 2003), que deslocaram o conceito de "verdade" e "totalidade" ao concebê-las sob o prisma do relativismo e da pluralidade que marca variadas interpretações, mutáveis a depender do local em que ocorrem. Tais noções são amplamente discutidas na arena dos debates sobre identidade no campo dos estudos culturais, sendo articuláveis à discussão em torno da noção de outro termo com o prefixo "pós": o pós-moderno.

Nesse sentido, pondera-se que o pós-método emerge a partir de um descentramento. Essa noção, cara ao pensamento pós-estruturalista, pode ser ilustrada pelas considerações de Jacques Derrida (2002) em A estrutura, o signo e o jogo no discurso das ciências humanas, acionadas, neste artigo, para pensar o descentramento que ocorreu no campo dos métodos de ensino de línguas estrangeiras. Esse pensador assinala, após um tom de relativismo, que "toda história do conceito de estrutura [...] tem de ser pensada como uma série de substituições de centro para centro, um encadeamento de determinações do centro" (DERRIDA, 2002, p. 231). Esse centro, para Derrida, não tem uma condição natural, mas sim naturalizada, ou seja, construída, e, portanto, o centro e 
noções como a de origem são uma forma de "discurso" (DERRIDA, 2002, p. 232), "isto é, sistema no qual o significado central originário ou transcendental nunca está absolutamente presente fora de um sistema de diferenças" (DERRIDA, 2002, p. 232).

Sob o conceito de descentramento, a leitura de textos como TESOL methods: changing tracks, challenging changes, de Kumaravadivelu (2006), desloca pressupostos que situam um método a exemplo do Método Comunicativo como adaptável a qualquer contexto, como se fosse possível contemplar, através dele, as idiossincrasias dos mais variados locais. Em torno desse assunto, Kumaravadivelu (2006) cita o questionamento de alguns autores sobre o pretenso universalismo atribuído a esse método e alude à visão de Chick de que incide sobre a escolha desse método certo "etnocentrismo inocente" (KUMARAVADIVELU, 2006, p. 63, tradução nossa), expresso na crença de que o método adequado ao contexto europeu e estadunidense é também adequado ao contexto sul-africano. A ponderação de Chick leva a pensar diversas experiências em sala de aula em que, diante da não conformação a modelos ou métodos hegemônicos, sujeitos foram vistos como incapazes de aprender, por serem esses métodos vistos como o padrão e o que não se adequa a eles, a exceção.

Em reta linha com o pensamento de Kumaravadivelu, tanto no PROFICI quanto no NucLi UFBA, a coordenação pedagógica dos monitores e professores está atenta aos variados modos e caminhos de aprendizagem, às implicações de ensinar língua inglesa em contexto pós-colonial e aos discursos em torno do imperialismo, principalmente o imperialismo linguístico.

As questões de poder subjacentes à educação, enunciadas por Paulo Freire (2011), estão presentes em discussões nas sessões de formação, em que são abordadas estratégias cujo ponto de partida é a gama de experiências dos aprendizes e seu conhecimento prévio, como requerem princípios freireanos e aqueles do Modelo Experiencial ou Construtivista (NUNAN, 1999). Nesses princípios, destacam-se a importância dada ao conhecimento prévio dos aprendizes, o desenvolvimento de sua autonomia, a competência de negociação de significado, o aprendizado de habilidades de forma integrada e o olhar crítico em relação à relevância social do que é ensinado. Tais aspectos também estão em alinhamento com as Macroestratégias, de Kumaravadivelu (2003).

É importante sublinhar que as estratégias supracitadas se conjugam a variadas outras, denotando que as orientações pedagógicas não têm em tela um único método. 
Apesar de, no PROFICI, haver um método norteador, o Comunicativo, materializado pelo livro didático adotado nos cursos de inglês, a série Interchange, princípios e técnicas de outros métodos e recriações e adaptações do material são encorajados para contemplar as necessidades dos aprendizes.

Entre atividades não convencionais desenvolvidas no PROFICI, destaca-se o uso de literatura e outras mídias. A utilização de textos literários imprime um diferencial em relação aos materiais convencionalmente usados em aulas que seguem o Método Comunicativo (BRUN, 2004), figurando como um aporte profícuo para abordar aspectos interculturais e reconstruir a identidade do aprendiz como falante de uma língua estrangeira, uma vez que falar outro idioma implica também em "simbolizar em duas línguas" (BRUN, 2004, p. 83). A simbolização é potencializada através de textos literários e outras narrativas, a exemplo de filmes e séries, afinados à ficcionalização já presente nas aulas de língua estrangeira pela criação de situações imaginárias para fins de contextualização e o ato de contar e fazer de conta, em que os aprendizes são comumente envolvidos (BRUN, 2004). Com a literatura, empreende-se um jogo de alteridade em que a projeção na história lida leva a uma imersão na cultura do outro com ressignificações na própria identidade cultural.

Ao lado dos argumentos apresentados por Brun, usados em algumas sessões de formação do PROFICI, são ensinadas variadas formas de abordagem do texto literário, para além da habilidade de leitura. Assim, há, no repertório de experiências com a literatura em aulas do PROFICI, o uso de um enredo como modo de sensibilização e aquecimento para um tema, a escrita de textos que recriam o final de um conto ou um romance, discussões sobre o desenrolar de uma narrativa ou interpretações sobre um poema, entre outras atividades.

As reflexões em torno da literatura e outras mídias fazem parte também do escopo de temas tratados em sessões de formação pedagógica e planejamento de aulas do NucLi UFBA. Embora haja o predomínio do Inglês para Fins Específicos e se sobressaia a noção de especificidade, o NucLi fornece uma pluralidade de possibilidades de ensino por não adotar um método e um livro-texto predefinidos. Dessa forma, os professores não só planejam as aulas como também elaboram materiais para elas e, por isso, estão em constante exercício de criatividade e busca de afinação entre os propósitos do curso e o perfil dos aprendizes. Muito comumente, literatura, seriados e filmes são usados como 
forma de introdução a um tema ou mesmo como parte de atividades voltadas a reflexões sobre aspectos interculturais, fundamentais para estudantes que almejam fazer intercâmbio e desejam adentrar o universo simbólico da comunicação e produção de sentido em língua estrangeira.

Ainda no que se refere ao NucLi, a possibilidade de criar materiais leva os professores, como investigadores (FREIRE, 2011), a analisarem o perfil dos aprendizes, através de um diagnóstico nas primeiras aulas e, com base nele, reconfigurarem temas e repensarem estratégias para um ensino de caráter particularizado, sem desconsiderar o propósito guarda-chuva do NucLi: o ensino de inglês para fins acadêmicos.

No que se refere ao Ensino de Línguas para Fins Específicos (ELFE), de acordo com Guimarães (2014), ele "se aplica ao ensino de línguas (materna ou estrangeira), direcionado para lidar em determinada situação-alvo, e estendendo-se ao ensino de línguas em contextos educacionais de natureza específica". O direcionamento para situações pontuais remonta ao século XVIII quando o Marquês de Pombal instituiu as "Aulas de Comércio" (GUIMARÃES, 2014), cuja finalidade era ensinar língua estrangeira para situações relativas ao comércio, seguindo o método de tradução e gramática, sob a influência da forma como as línguas clássicas eram ensinadas.

Atravessando séculos, o ensino de línguas para fins específicos ainda é concebido sob a sombra dos seus primórdios e, não raro, é atrelado ao ensino instrumental para leitura, em que prevalecem a tradução e o conhecimento gramatical. Com o IsF, o ELFE ganha outra dimensão, podendo ser relacionado a um dos Parâmetros da Pedagogia do Pós-método configurados por Kumaravadivelu (2003), a saber: o Parâmetro da Particularidade. Esse parâmetro antecede dois outros: o da Praticalidade e da Possibilidade, que, articulados, delineiam aspectos fundamentais da referida Pedagogia.

O Parâmetro da Particularidade aponta para a relação entre o ensino e o contexto que circunscreve aprendizes e professores; o da praticalidade firma a relação que deve existir entre a teoria que alicerça o ensino e o seu alicerce, ou seja, a prática em sala de aula; o da possibilidade grifa as implicações políticas do ensino e atribui a este o caráter de agente de transformação social, ao modo da Pedagogia Crítica. É importante frisar a forte relação entre esses três parâmetros ao se pensar que não haveria particularidade em um contexto em que o professor seguisse teorias engendradas por outrem ou desconhecesse o papel social do ensino. 
Os parâmetros descritos por Kumaravadivelu fazem parte dos princípios que regem as estratégias de ensino usadas no NucLi e no PROFICI com reverberações que variam de acordo com os objetivos específicos ou convergentes desses espaços de aprendizagem de língua estrangeira. Conjugados aos propósitos dos cursos, eles têm promovido um dinamismo na construção das aulas e garantido a sua efetividade em resultados convertidos no aprendizado de língua estrangeira. Esse aprendizado é orquestrado por objetivos voltados à formação de falantes que dominem não apenas um idioma de um modo geral ou para um fim específico, mas, também, tenham uma percepção crítica acerca do que podem alcançar através desse idioma e, acima disso, do que podem ajudar a sociedade a atingir mediante o conhecimento de si e do outro. Tal conhecimento advém de um jogo de alteridade que potencializa a identidade cultural e que tem como um dos seus passaportes a língua estrangeira.

Apesar das convergências, há diferenças entre o ensino de língua estrangeira no PROFICI e no NucLi. A título de ilustração dessas, menciona-se uma típica aula de inglês geral, ministrada no PROFICI, em que o aprendiz estuda como perguntar sobre e descrever o local onde mora. Essa function, no NucLi, por sua vez, teria como propósito aprender como descrever o campus através da estratégia de stretched output (RICHARDS, 2008). Como as aulas do NucLi são, em sua maioria, designadas para estudantes que já têm conhecimento do idioma a partir do nível A2, em sua maioria, as aulas são planejadas tendo como um dos procedimentos iniciais a ativação do conhecimento prévio, que é, então, estendido (stretched) em situações de produção (output) através de conteúdo em contexto acadêmico, não comumente abordado em cursos gerais de idiomas. Tal estratégia tem como objetivo a prática do que o aprendiz estudou na aula para ampliação do seu conhecimento da língua, incorporando nesse novo conteúdo um enfoque acadêmico. No PROFICI, functions como a mencionada são ensinadas como parte de interações cotidianas não necessariamente relacionadas a um contexto acadêmico.

Outro exemplo de redimensionamento dos planos de aula em alinhamento com os objetivos de ensino de inglês para fins específicos no NucLi é a elaboração de objetivos e estratégias designados para que o aprendiz desenvolva competências necessárias à participação em debates acadêmicos. Um ponto de convergência é a presença dos debates em aulas ministradas no PROFICI também nos níveis intermediário e intermediário superior. Todavia, nesse programa, os aprendizes são envolvidos em discussões sem enfoque necessariamente acadêmico e os monitores têm em perspectiva o aprendizado de 
determinadas functions e negociação de significado em interações com ativação e/ou construção do conteúdo que deve ser aprendido no nível em que o aprendiz se encontra.

No NucLi, por seu turno, na elaboração de planos para esse tipo de curso, os professores sugerem temas que apresentam considerável relevância social, mas eles são formatados com aspectos que os direcionam aos propósitos da internacionalização de uma universidade, que se referem ao preparo para situações de interação acadêmica em debates resultantes de palestras, aulas, apenas para citar algumas situações. Como exemplo, cita-se o tema Gender Roles (Papéis de Gênero). Os caminhos iniciais para elaboração da aula sobre esse tema apontavam para um debate a partir de exemplos e discussões com base em filmes e seriados. Para imprimir um tom acadêmico e não perder o objetivo geral do IsF, a coordenação sugeriu o uso de excertos de um texto teórico e a contextualização da discussão como parte de uma aula que seria ministrada em uma disciplina de Ciências Sociais ou de Letras, ou mesmo que faria parte de um seminário sobre o assunto.

É possível notar, no processo de construção das aulas no NucLi, que envolve elaboração de planos de aula e desenvolvimento de materiais, que alguns professores tendem a usar estratégias e propor conteúdos afinados com o ensino geral de inglês. Essa tendência encontra uma justificativa no predomínio de cursos de tal caráter e mesmo nos propósitos de disciplinas mais diretamente voltadas a metodologias de ensino de língua estrangeira na universidade. Nelas, a exemplo de Estágio Supervisionado I de Língua inglesa, a ementa consiste no ensino de habilidades e estudos de questões teóricometodológicas para diferentes contextos de aprendizagem, entre os quais o ensino de inglês para fins específicos raramente figura. Nesse sentido, a formação recebida no NucLi suplementa o repertório de conhecimentos sobre estratégias de ensino dos graduandos e pós-graduandos de Letras e consiste em uma etapa fundamental para o desenvolvimento das aulas e o desenvolvimento profissional desses estudantes, que, ao promoverem o acesso de tantos sujeitos ao aprendizado de um idioma, se beneficiam com as possibilidades de alçarem voos por vias outrora desconhecidas. Assim, frisa-se que o conhecimento é sempre uma meta e um caminho e advoga-se pelo caráter suplementar que o PROFICI e o NucLi têm para a formação de futuros professores e de falantes de língua estrangeira. 


\section{Ponto de chegada para outras escalas}

As discussões neste artigo foram feitas com o objetivo de compartilhar reflexões e experiências em dois contextos de ensino de língua estrangeira, com ênfase em língua inglesa, na Universidade Federal da Bahia. Esse compartilhamento tem em perspectiva a importância de imprimir outras cores ao debate em torno do ensino de línguas estrangeiras no Brasil, que fujam à monocromia atrelada a uma história de monolinguismo no país e de ensino de aulas pautadas em um único método.

Se outrora o acesso ao aprendizado de língua inglesa, aqui enfocada, era visto sob a sombra do elitismo e da influência de países hegemônicos, ter o relato de experiências de ampla oferta de cursos gratuitos e de formação de professores, marcada por autonomia e pensamento crítico, operam uma descontinuidade e desconstrução de tal elitismo e da dependência.

O caminho para uma reversão ainda maior é longo, mas as etapas trilhadas até então trazem um otimismo necessário a um país que percebeu, com o CsF, que não se constrói ciência e uma nação sem fronteiras com barreiras linguísticas. É preciso capacitar o país para interações com outros países através do aprendizado de línguas estrangeiras. Almeja-se que as interações em salas de aula na UFBA e em outras universidades no país sejam a metáfora e a ponte para essa grande meta.

\section{Referências}

ABREU-E-LIMA, Denise Martins de; FILHO, Waldenor Barros Moraes; BARBOSA, Wagner José Corradi; BLUM, Avram Stanley. O Programa Inglês sem Fronteiras e a política de incentivo à internacionalização do ensino superior brasileiro. In: SARMENTO, Simone; ABREU-E-LIMA, Denise Martins de; FILHO, Waldenor Barros Moraes (Org.). Do Inglês sem Fronteiras ao Idiomas sem Fronteiras: a construção de uma política linguística para a internacionalização. Belo Horizonte: Editora UFMG, 2016, p. 19-46.

BORGES, Rovênia Amorim. A interseccionalidade de gênero, raça e classe no programa Ciência sem Fronteiras: um estudo sobre estudantes brasileiros com destino aos EUA. Dissertação (Mestrado Profissional em Educação). Brasília: Universidade de Brasília, 2015.

BRASIL. Programa Ciência sem Fronteiras. Decreto $\mathbf{n}^{\circ}$ 7.642, 13 de dezembro de 2011. Disponível em: <http://www.planalto.gov.br/ccivil_03/_ato20112014/2011/decreto/d7642.htm>. Acesso em: 3 dez. 2017. 
RELATÓRIO No - CCT, DE 2015. Disponível em:

<http://www19.senado.gov.br/sdleg-getter/documento/download/57327a74-6863-4c7fb1e6-8c60bfc5bc3a>. Acesso em: 12 dez. 2017.

Portaria Normativa $\mathbf{n}^{\circ}$ 30/2016. Disponível em:

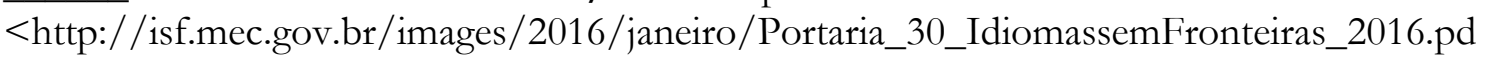
f>. Acesso em: 4 dez. 2017.

BROWN, Douglas. Teaching by principles: an interactive approach to language pedagogy. New York: Pearson Education, 2007.

BRUN, Milenna. (Re)construção identitária no contexto da aprendizagem de línguas estrangeiras. In: MOTA, Kátia; SCHEYERL, Denise (Org.). Recortes interculturais na sala de aula de línguas estrangeiras. Salvador: EDUFBA, 2004, p. 73-104.

DERRIDA, Jacques. A estrutura, o signo e o jogo no discurso das ciências humanas. In: A escritura e a diferença. Trad. Maria Beatriz Marques Nizza da Silva. São

Paulo: Editora Perspectiva, 2002, p. 229-249.

FREIRE, Paulo. Pedagogia do oprimido. Rio de Janeiro: Paz e Terra, 2011.

GUIMARÃES, Renata Mourão. O ensino de línguas para fins específicos (ELFE) no Brasil e no mundo: ontem e hoje. HELB: História do Ensino de Línguas no Brasil. Ano 8 no 8 - 1/2014. Disponível em: <http://www.helb.org.br/index.php/revista-helb/ano-8no-8-12014/227-o-ensino-de-linguas-para-fins-especificos-elfe-no-brasil-e-no-mundoontem-e-hoje>. Acesso em: 21 dez. 2017.

HALL, Stuart. A identidade cultural na pós-modernidade. 7 ed. Trad. Tomaz Tadeu da Silva; Guaracira Lopes Louro. Rio de Janeiro: DP \& A, 2003.

IOSIF, Ranilce Guimarães; ZARDO, Sinara Pollom; SANTOS, Aline Veiga dos; OLIVEIRA, Lilian Mendonça de. Programa Ciência sem Fronteiras: a tradução da política linguística de internacionalização brasileira no Canadá. Interfaces Brasil/Canadá. Canoas, v. $16, \mathrm{n}^{\circ} 1,2016$, p. $16-39$.

KUMARAVADIVELU, B. Beyond methods: macrostrategies for language teaching. New Haven; Londres: Yale University Press, 2003. $\mathrm{n}^{\circ} 1,2006$.

TESOL Methods: changing tracks, challenging trends. TESOL Quarterly, v. 40,

MANÇOS, Guilherme de Rosso; COELHO, Fernando de Souza. Internacionalização da ciência brasileira: subsídios para avaliação do programa Ciência sem Fronteiras. Revista brasileira de políticas públicas e internacionais, v. 2, n 2, 2017.

NUNAN, David. Second language teaching and learning. Boston: Heinle \& Heinle Publishers, 1999. 
PAIVA, Thaís. Impasses no Ciência Sem Fronteiras. Disponível em: $<$ http://www.cartaeducacao.com.br/reportagens/impasses-no-ciencia-sem-fronteiras/ $>$. Acesso em: 11 nov. 2017.

RICHARDS, Jack C. Teaching listening and speaking: from theory to practice. New York: Cambridge, 2008.

\begin{abstract}
From a theoretical-explanatory perspective, this article addresses English language teaching in post-method times and in the era of expansion of actions aimed at the internationalization process of universities, having as object of analysis strategies used in classrooms of the courses offered by an institutional program of foreign languages teaching of the Federal University of Babia (PROFICI) and the Nucleus of Languages of this university, within the Languages without Borders Program. In its scope, convergences and specificities of these two contexts are discussed, showing the fruitful articulation of their actions, which express the protagonism of the area of Languages through the teaching of foreign languages as the foundation for the internationalization process.
\end{abstract}

Keywords: NucLi. PROFICI. Teaching. PostMethod. Internationalization

Recebido em: 01/01/2018.

Aceito em: 04/06/2018. 